\title{
Analisis faktor yang berhubungan dengan pelaksanaan standar APN oleh bidan puskesmas PONED Padang Pariaman
}

\author{
Merisa Riski ${ }^{1}$, Yuniar Lestari ${ }^{2}$, Ulvi Mariati ${ }^{3}$ \\ 1. Program Studi Pascasarjana Ilmu Kebidanan, Fakultas Kedokteran, Universitas Andalas; 2. \\ Departemen Kesehatan Masyarakat, Fakultas Kedokteran, Universitas Andalas; 3. Jurusan Kebidanan \\ Politeknik Kesehatan Kementerian Kesehatan Padang
}

Korespondensi: Merisa Riski; email: merisa rizki@yahoo.com

\begin{abstract}
Abstrak
Tujuan: Untuk menganalisis faktor yang berhubungan dengan pelaksanaan penerapan standar asuhan persalinan normal oleh bidan puskesmas PONED Padang Pariaman. Metode: Penelitian ini menggabungkan 2 jenis penelitian (mixed method) yang didahului oleh penelitian kuantitatif dengan desain cross sectional, sampel 74 bidan puskesmas PONED. Analisis data menggunakan uji Chi-Square dan uji regresi logistik. Kemudian dilanjutkan dengan penelitian kualitatif. Hasil: Hasil penelitian menunjukkan sebagian besar bidan puskesmas pelaksanaan penerapan standar asuhan persalinan normal yang baik. Faktor yang memiliki hubungan bermakna dengan pelaksanaan penerapan standar asuhan persalinan normal adalah pengetahuan, sikap, persepsi kepemimpinan, motivasi, persepsi supervisi kepala puskesmas, dan persepsi organisasi profesi/IBI. Hasil penelitian juga menunjukkan persepsi supervisi kepala puskesmas sebagai faktor dominan yang mempengaruhi pelaksanaan penerapan standar asuhan persalinan normal secara baik 7,649 kali dibandingkan dengan komitmen variabel lainnya. Simpulan: Persepsi supervisi kepala puskesmas sebagai faktor dominan yang berhubungan pelaksanaan penerapan standar APN oleh bidan puskesmas PONED. Disarankan agar mempertahankan keterampilan bidan terutama dalam melaksanakan penerapan standar asuhan persalinan normal.
\end{abstract}

Kata kunci: standar APN; bidan; puskesmas PONED

\begin{abstract}
Objective: To analyze factors related to the implementation of normal delivery care standards by midwives at PONED Puskesmas Padang Pariaman. Methods: This study combines 2 types of research (mixed method) which is preceded by quantitative research with a cross-sectional design, sample is 74 midwives PONED Puskesmas. Data analyzes using the chi-square test and logistic regression test then proceed with qualitative research. Results: The results of the study showed that most Puskesmas' midwives were implementing good normal delivery care standards. Factors that had a significant relationship with the implementation of normal delivery care standards were knowledge, attitudes, leadership perceptions, motivation, perception of supervision of the Head of the Puskesmas, and perception of professional organizations/IBI. The results also showed the perception of the supervision of the Head of the Puskesmas as a dominant factor affecting the implementation of the normal implementation of normal delivery care standards 7.649 times compared to another variable. Conclusions: The perception of the supervision of the Head of the Puskesmas as a dominant factor is related to the implementation of the APN standard by the PONED Puskesmas' midwife. It is recommended to maintain the skills of midwives, especially in carrying out the application of normal delivery care standards.
\end{abstract}

Keywords: APN standards; midwife; PONED Puskesmas 


\section{PENDAHULUAN}

Survei Demografi Kesehatan Indonesia (SDKI) tahun 2007 angka kematian Ibu 228 per 100.000 kelahiran hidup, sementara tahun 2012 kematian ibu di Indonesia melonjak mencapai 359 per 100 ribu. Pada tahun 2019 ditargetkan AKI menjadi 306 per 100.000 kelahiran hidup. $^{1}$

Hasil laporan dari fasilitas pelayanan kesehatan Dinas Kesehatan Provinsi Sumatera Barat tahun 2017, kasus kematian ibu meliputi ibu hamil, ibu bersalin dan ibu nifas sebanyak 107 orang, sedangkan kasus kematian bayi juga mengalami peningkatan sebanyak 700 orang. $^{2}$

Berdasarkan data Pemantauan Wilayah Setempat-Kesejahteraan Ibu dan Anak (PWS-KIA) di Puskesmas Kabupaten Padang Pariaman angka kematian bayi pada tahun 2016 sebanyak (1,29\%) dan tahun 2017 mengalami peningkatan yaitu (1,65\%). Sedangkan angka kematian ibu (AKI) pada tahun 2016 sebesar 129,29/100.000 kelahiran hidup dan tahun 2017 mengalami peningkatan yaitu $164,05 / 100.000$ kelahiran hidup. $^{3}$

Menurunkan Angka Kematian Ibu (AKI) dan Angka Kematian Bayi (AKB), puskesmas berkomitmen melalui upaya kesehatan ibu, anak gizi, promosi kesehatan serta penyelenggaraan puskesmas Pelayanan Obstetrik dan Neonatal Emergensi Dasar (PONED). ${ }^{1}$ Penyelenggaraan puskesmas (PONED) merupakan tersedianya tenaga penolong persalinan yang terlatih untuk dapat memberikan pelayanan yang bermutu, diperlukan adanya standar pelayanan kebidanan. ${ }^{4}$

Studi pendahuluan yang dilakukan melalui pengamatan pada dokumentasi partograf terhadap 10 orang bidan di Puskesmas Kabupaten Padang Pariaman, 6 orang (60\%) belum melaksanakan pelayanan persalinan sesuai dengan standar Asuhan Persalinan Normal yang ada dimana bidan sering lupa memberitahu kepada ibu bahwa penolong akan menyuntikkan oksitosin (agar uterus berkontraksi dengan baik) dan mematikan kelengkapan alat untuk pertolongan persalinan karena peralatan yang ada di ruangan PONED sudah tersedia di ruangan persalinan tersebut. Begitu juga dengan penggunaan partograf, bidan mengisi partograf pada grafik pembukaan serviks dan grafik Denyut Jantung Janin (DJJ) setelah pertolongan persalinan selesai. Semestinya partograf diisi setiap selesai evaluasi untuk memantau kemajuan persalinan dan kesejahteraan janin dalam uterus. Sedangkan wawancara secara acak dilakukan 6 bidan, terdapat 5 bidan mengalami kesulitan dalam melakukan pengisian partograf dengan alasan rumit dan menyita banyak waktu.

Penerapan dalam mutu layanan kesehatan ibu antara lain melalui penetapan standar pelayanan, prosedur tetap, penilaian kinerja, pelatihan klinis dan kegiatan audit maternal-perinatal (AMP). ${ }^{4}$ Agar bidan dapat memberikan pelayanan yang bermutu dan sesuai kompetensi yang dimiliki serta wewenang yang diberikan, maka hendaknya selalu berpedoman pada 
standar pelayanan kebidanan yang ada. Selain itu, faktor yang dapat mempengaruhi hasil pelayanan kesehatan yaitu sarana dan prasarana.

Berdasarkan penelitian oleh Ratifah (2006), dikatakan bahwa pengetahuan $(p=0,011)$, persepsi kepemimpinan $(p=0,007)$, motivasi $(p=0,00)$, supervisi kepala puskesmas $(p=0,006)$ dan supervisi IBI $\quad(p=0,004)$ mempunyai hubungan dengan pelaksanaan penerapan standar asuhan persalinan normal. ${ }^{1}$

Data tahun 2017 Dinas Kesehatan Kabupaten Padang Pariaman bahwa jumlah sarana pelayanan kesehatan Puskesmas yaitu 25 unit yang terbagi atas 15 Puskesmas rawat jalan, 8 Puskesmas PONED dan 2 Puskesmas rawat inap. Jumlah tenaga bidan keseluruhannya 430 orang dengan rincian: 234 orang $(54,42 \%)$ Bidan PNS, 11 orang (2,58\%) bidan PTT, 185 orang $(43,02 \%)$ bidan desa. $^{5}$

Meningkatkan kompetensi bidan dan mutu pelayanan, bidan diharuskan mengikuti pendidikan berjenjang melalui jalur khusus DIII Kebidanan (AKBID). Dinas Kesehatan bekerja sama dengan organisasi profesi Ikatan Bidan Indonesia (IBI) Kabupaten Padang Pariaman menyelenggarakan pelatihan, yang salah satunya difokuskan pada pelatihan Asuhan Persalinan Normal (APN). ${ }^{4}$ Sampai bulan Desember 2017 dari 430 Bidan yang ada di Puskesmas Wilayah Kerja Dinas Kesehatan Kabupaten Padang Pariaman 265 orang bidan (61,63\%) telah mengikuti pelatihan Asuhan Persalinan Normal. Sedangkan Puskesmas PONED di Kabupaten Pariaman memiliki tenaga bidan 93 orang. Adapun status kepegawaian $100 \%$ adalah Pegawai Negeri Sipil (PNS) dengan kualifikasi pendidikan: DIII Kebidanan 54 orang (68,8\%), DIV Bidan 30 orang $(32.26 \%)$, S1 Sederajat 2 orang $(2,08 \%)$. Bidan yang mengikuti pelatihan Asuhan Persalinan Normal sebanyak 49 orang $(52,69 \%){ }^{5}$

Tujuan umum pelatihan APN adalah tercapainya tingkat kompetensi keterampilan seperti yang diinginkan, penguasaan pengetahuan yang diperlukan dan perubahan perilaku yang mendukung pemberian pelayanan yang berkualitas sesuai dengan standar pelayanan. 6 Sejalan dengan penelitian Wattimena (2008) diketahui bahwa ada hubungan bermakna antara pelatihan APN dengan pelaksanaan penerapan standar asuhan persalinan normal. Pelaksanaan standar asuhan persalinan normal yang baik banyak didapatkan pada bidan yang pernah mengikuti pelatihan. ${ }^{7}$

Berdasarkan hasil wawancara dengan 12 orang bidan yang belum mengikuti pelatihan Asuhan Persalinan Normal dengan alasan keterbatasan biaya, waktu dan tempat. Untuk mengikuti pelatihan APN yang biayanya cukup mahal bidan harus membayar dengan uang pribadi tanpa ada bantuan dari instansi terkait (pihak Puskesmas). Selain itu keterbatasan waktu untuk mengikuti pelatihan yang cukup lama dan tidak dapat izin untuk mengikuti pelatihan menjadi alasan para bidan.

Berdasarkan latar belakang yang telah peneliti uraikan tersebut, maka peneliti 
tertarik untuk melakukan penelitian tentang analisis faktor yang berhubungan dengan pelaksanaan penerapan standar Asuhan Persalinan Normal (APN) oleh bidan Puskesmas PONED di Wilayah Kerja Dinas Kesehatan Kabupaten Padang Pariaman.

\section{METODE}

Jenis penelitian ini merupakan penelitian kombinasi yaitu metode penelitian yang menggabungkan antara metode penelitian kuantitatif dan kualitatif dengan pendekatan Explanatory Research. Penelitian kuantitatif menggunakan desain cross sectional, sampel yang digunakan 74 bidan dengan teknik proportional random sampling, ${ }^{8}$ untuk menentukan besar sampel menggunakan rumus: $\mathrm{n}=\mathrm{X} / \mathrm{N} \times \mathrm{Ni}$. Pengumpulan data dilakukan dengan data primer yaitu dengan menggunakan kuesioner dan observasional dan data sekunder yaitu dengan cara menelusuri dan menelaah data yang akan diteliti. Analisa data yang digunakan yaitu analisis univariat dilakukan dengan menghitung distribusi frekuensi dan proporsinya, analisa bivariat dilakukan untuk melihat ada hubungan variabel independen dengan variabel dependen dengan menggunakan uji Chi-Square dengan tingkatan signifikasi $\alpha=0,05$.

Variabel dependen dalam penelitian adalah pelaksanaan penerapan standar asuhan persalinan normal oleh bidan puskesmas PONED dan variabel independen adalah pengetahuan, sikap, persepsi kepemimpinan, motivasi, persepsi supervisi kepala puskesmas dan persepsi supervisi organisasi profesi yaitu IBI.

Data pengetahuan didapat dengan cara meminta responden untuk mengisi kuesioner. Kategori pengetahuan dikatakan tinggi jika jumlah skor $\geq 60 \%$ dan dikatakan rendah jika jumlah skor $<60 \%{ }^{7}$ Kategori sikap dikatakan positif $\geq 65,62$ dari skor total 100 dan negatif $<65,62$ dari skor total $100 .^{8}$ Kategori persepsi dikatakan baik $\geq 65,62$ dari skor total 100 dan dikatakan kurang baik , <65,62\% dari skor total $100 .^{8}$ Kategori motivasi dikatakan tinggi, jika skor $\geq 65,62$ dari skor total 100 dan dikatakan rendah, jika $<65,62$ dari skor total $100 .^{8}$ Kategori persepsi supervisi pimpinan puskesmas dikatakan baik, jika skor $\geq 65,62$ dari skor total 100 dan dikatakan kurang baik, jika skor <65,62 dari skor total $100 .^{8}$ Kategori supervisi organisasi profesi yaitu IBI dikatakan baik jika skor $\geq 65,62$ dari skor total 100 dan dikatakan kurang baik, jika skor <65,62 dari skor total $100 .^{8}$ Kategori pelaksanaan penerapan standar asuhan persalinan normal oleh bidan dikatakan cukup, $60-75 \%$ dan dikatakan baik $>75 \% .^{7}$

Penelitian kualitatif dilaksanakan untuk menggali informasi mendalam mengenai pelaksanaan penerapan standar APN oleh bidan puskesmas PONED di Wilayah Kerja Dinas Kesehatan Kabupaten Padang Pariaman dengan cara wawancara mendalam, observasi dan Focus Group Discussion (FGD). Pemilihan informan dalam penelitian ini dengan menggunakan teknik proposive sampling. Informan dalam wawancara mendalam adalah 
kepala seksi Sumber Daya Kerja di Dinas Kesehatan Kabupaten Padang Pariaman, Kepala Puskesmas PONED, Organisasi profesi IBI, Bidan Koordinasi PONED dan informan FGD dan Observasi dilakukan kepada bidan puskesmas PONED sebanyak 16 orang.

Teknik pengumpulan data kualitatif ini dilakukan dengan cara observasi melalui pengamatan bebas, mencatat apa yang tertarik dengan membuat catatan lapangan, melakukan analisis dan kemudian dibuat kesimpulan. Pengumpulan data wawancara mendalam yang digunakan dalam penelitian ini wawancara berstruktur dan wawancara mendalam agar fokus pada pokok permasalahan penelitian. Pengumpulan data dengan FGD dengan cara menggali informasi yang berkaitan erat dengan aspek-aspek pelaksanaan penerapan standar asuhan persalinan normal oleh bidan, serta untuk menjawab masalahmasalah manajemen atau kendala-kendala yang dihadapi dalam pelaksanaan penerapan standar APN.

\section{HASIL DAN PEMBAHASAN}

Sebagian besar dari responden memiliki pengetahuan tinggi $(79,7 \%)$ dalam pelaksanaan penerapan standar asuhan persalinan normal. Analisis triangulasi: bidan memiliki pengetahuan yang baik dalam pelaksanaan penerapan standar asuhan persalinan normal. Hasil peneliti melakukan penelitian menggunakan uji statistik ada hubungan bermakna antara pengetahuan dengan pelaksanaan penerapan standar asuhan persalinan normal $(p<0,05)$. Hasil penelitian ini sejalan dengan penelitian yang dilakukan oleh Subekti (2014) bahwa ada hubungan pengetahuan dengan kinerja bidan dalam pelaksanaan penerapan standar asuhan persalinan normal. ${ }^{9}$ Seorang penolong persalinan memiliki kemampuan dan keterampilan yang baik, diantaranya adalah penatalaksanaan persalinan, kelahiran, masa nifas, mengetahui prosedur pendiagnosaan, penatalaksanaan atau pedoman rujukan ibu dan bayi ke tingkat asuhan yang lebih tinggi. ${ }^{10}$

Sebagian besar dari responden memiliki sikap positif (74,3\%) dalam pelaksanaan penerapan standar asuhan persalinan normal. Analisis triangulasi: bidan memiliki sikap yang baik dalam pelaksanaan penerapan standar asuhan persalinan normal. Hasil peneliti melakukan penelitian menggunakan uji statistik ada hubungan bermakna antara sikap dengan pelaksanaan penerapan standar asuhan persalinan normal $(p<0,05)$. Wattimena (2008) bahwa sikap yang meliputi sebagai bidan yang bekerja di Rumah Sakit, semua informasi perasaan positif senang, namun tanggapan pertolongan persalinan dengan penerapan standar APN belum baik/masih kurang. ${ }^{7} \quad$ Sikap cenderung untuk merespons (secara positif atau negatif) terhadap orang, objek atau situasi tertentu. Sikap mengandung penilaian yang emosional (senang, sedih, benci dan lain-lain). Sikap merupakan reaksi atau respon yang masih tertutup dari seseorang 
terhadap suatu stimulus atau objek. Sikap sering diperoleh dari pengalaman sendiri atau orang lain yang paling dekat. ${ }^{11}$

Sebagian besar dari responden memiliki persepsi terhadap kepemimpinan yang baik $(82,4 \%)$ dalam pelaksanaan penerapan standar asuhan persalinan normal. Analisis triangulasi: bidan memiliki persepsi kepemimpinan yang baik, dimana bidan bisa bekerja sama secara optimal dalam melaksanakan penerapan standar APN. Hasil peneliti melakukan penelitian menggunakan uji statistik ada hubungan bermakna antara persepsi kepemimpinan dengan pelaksanaan penerapan standar asuhan persalinan normal $(p<0,05)$.
Penelitian ini sama dengan penelitian Ratifah (2006) bahwa persepsi kepemimpinan berhubungan bermakna dengan pelaksanaan penerapan standar asuhan persalinan normal. Artinya tinggi rendahnya persepsi kepemimpinan akan mempengaruhi pelaksanaan persepsi kepemimpinan. ${ }^{1}$ Kepemimpinan seorang pimpinan akan efektif jika bawahan bersedia menerima pengarahan dari pimpinannya. Bawahan sangat menentukan kedudukan pimpinan dan menentukan pula jalannya proses kepemimpinan. Kepemimpinan menyangkut pembagian kekuasaan yang tidak seimbang antara pemimpin dan bawahan. ${ }^{12}$

Tabel 1. Analisis Faktor yang Dominan yang Berhubungan dengan Pelaksanaan Penerapan Standar Asuhan Persalinan Normal

\begin{tabular}{lcccccc}
\hline Variabel & B & SE & Wald & df & Sig. & Exp(B) \\
\hline Persepsi Kepemimpinan & 1,507 & 0,797 & 3,573 & 1 & 0,059 & 4,514 \\
Motivasi & 1,468 & 0,771 & 3,625 & 1 & 0,057 & 4,339 \\
Persepsi supervisi Kepala Puskesmas & 2,035 & 0,818 & 6,185 & 1 & 0,013 & 7,649 \\
\hline
\end{tabular}

Sebagian besar dari responden memiliki motivasi tinggi (70,3\%) terhadap pelaksanaan penerapan standar asuhan persalinan normal. Analisis triangulasi: bidan memiliki motivasi yang baik dalam melaksanakan penerapan standar asuhan persalinan normal. Hasil peneliti melakukan penelitian menggunakan uji statistik ada hubungan bermakna antara motivasi dengan pelaksanaan penerapan standar asuhan persalinan normal $(p<0,05)$. Motivasi adalah suatu dorongan proses psikologi yang menimbulkan perilaku tertentu dan ikut menentukan intensitas, arah, ketekunan dan ketahanan pada perilaku tersebut sesuai tujuan yang ditetapkan. dorongan motivasi akan memberikan dampak yang langgeng bagi seorang bidan dalam melakukan tindakan secara efektif dan efisien untuk mencapai suatu tujuan yang telah ditetapkan. ${ }^{12}$

Sebagian besar dari responden memiliki persepsi supervisi kepala puskesmas dengan baik $(85,1 \%)$ terhadap pelaksanaan penerapan standar asuhan persalinan normal. Analisis triangulasi: bidan memiliki persepsi supervisi kepala puskesmas dengan baik dalam pelaksanaan penerapan standar asuhan persalinan normal. Hasil peneliti melakukan 
penelitian menggunakan uji statistik ada hubungan bermakna antara persepsi supervisi kepala puskesmas terhadap pelaksanaan penerapan standar asuhan persalinan normal $(p<0,05)$. Penelitian ini sama dengan peneliti Subekti (2014) bahwa ada berhubungan signifikan antara persepsi supervisi kepala puskesmas dengan kinerja bidan dalam pelaksanaan penerapan standar asuhan persalinan normal. ${ }^{9}$ Supervisi bertujuan untuk memastikan kegiatan yang dilaksanakan sesuai dengan tujuan. Dengan cara melakukan pengawasan terhadap pelaksanaan kegiatan tersebut. Supervisi dilakukan untuk memastikan kegiatan yang dilaksanakan sesuai dengan standar yang telah ditetapkan. ${ }^{12}$ Lebih separuh dari responden memiliki persepsi supervisi organisasi profesi/IBI dengan baik $(68,9 \%)$ terhadap pelaksanaan penerapan standar asuhan persalinan normal. Analisis triangulasi: bidan memiliki persepsi supervisi organisasi profesi dengan baik dalam pelaksanaan penerapan standar asuhan persalinan normal. Hasil peneliti melakukan penelitian menggunakan uji statistik ada hubungan bermakna antara persepsi supervisi organisasi profesi / IBI terhadap pelaksanaan penerapan standar asuhan persalinan normal $(p<0,05)$. sama dengan penelitian Ratifah (2006) bahwa ada hubungan signifikan antara persepsi supervisi organisasi profesi dengan pelaksanaan penerapan standar asuhan persalinan normal. ${ }^{1}$ Supervisi merupakan bentuk komunikasi yang bertujuan untuk memastikan kegiatan yang dilaksanakan sesuai dengan tujuan dengan cara melakukan pengawasan terhadap pelaksanaan kegiatan tersebut. Supervisi dilakukan untuk memastikan kegiatan yang dilaksanakan sesuai dengan standar yang telah ditetapkan. ${ }^{12}$

Berdasarkan tabel 1 bahwa Nilai Exponent beta $(\operatorname{expB})$ paling besar pada variabel persepsi supervisi kepala puskesmas adalah 7,649 artinya jika persepsi supervisi kepala puskesmas bisa diterapkan dengan baik maka pelaksanaan penerapan standar asuhan persalinan normal oleh bidan puskesmas PONED berpeluang tujuh kali lebih baik.

\section{SIMPULAN}

Kepada pihak terkait puskesmas PONED diharapkan, agar dapat mempertahankan pengetahuan bidan terhadap pelaksanaan penerapan standar asuhan persalinan norma melalui bidan mengikuti pelatihan yang relevan dan sesuai dengan bidangnya seperti pelatihan MU,APN dan PONED. Serta bekerja sama dengan organisasi profesi/IBI.

Bidan puskesmas PONED untuk mempertahankan keterampilan, terutama dalam melaksanakan persalinan normal sesuai dengan daftar tilik dan pengisian partograf yang benar untuk memantau kemajuan persalinan.

Peneliti selanjutnya, agar dilakukan penelitian yang lebih lanjut tentang efektivitas pelaksanaan penerapan standar APN seperti peningkatan kinerja bidan dalam pelaksanaan penerapan standar APN. 


\section{DAFTAR PUSTAKA}

1. Ratifah. Analisis Faktor-Faktor yang Berhubungan Dengan Pelaksanaan Penerapan Standar Asuhan Persalinan Normal (APN) oleh Bidan Puskesmas Rawat Inap di Kabupaten Bayumas. [Tesis]. Semarang: Program Pascasarjana Universitas Diponegoro; 2006.

2. Dinas Kesehatan Provinsi Sumatera Barat. Profil Dinas Kesehatan Tahun 2017. Kota Padang: Dinas Kesehatan Provinsi Sumatera Barat; 2017.

3. Dinas Kesehatan Kabupaten Padang Pariaman. Profil Kesehatan Kabupaten Padang Pariaman. Padang Pariaman: Dinas Kesehatan Kabupaten Padang Pariaman; 2018.

4. Sugiyono. Metode Penelitian Bisnis. Pendekatan Kuantitatif, Kualitatif, Kombinasi dan R\&D. Bandung: Alfabeta; 2017.

5. Dinas Kesehatan Kabupaten Padang Pariaman. Perencanaan Kebutuhan SDM Kesehatan Kabupaten Padang Pariaman Tahun 2017. Padang Pariaman: Dinas Kesehatan Kabupaten Padang Pariaman; 2017.

6. JNPK-KR. Pelatihan Klinik Asuhan Persalinan Normal. Jakarta: Departemen Kesehatan Republik Indonesia; 2017.

7. Wattimena M. Analisis Penerapan Standar Asuhan Persalinan Normal (APN) Oleh Bidan Di Rumah Sakit Umum Daerah Kabupaten Sorong Papua Barat Tahun 2008 (Studi Kualitatif). [Tesis]. Semarang: Program Pascasarjana Universitas Diponegoro; 2008.

8. Arikunto S. Prosedur Penelitian Suatu Pendekatan Praktik. Jakarta: Rineka Cipta; 2010.

9. Subekti SS, Widagdo L, Wulan LRK. Faktor-faktor Yang Kinerja Bidan Desa dalam Penerapan Standar Asuhan Kebidanan Ibu Bersalin di Kabupaten Semarang. Jurnal Manajemen Kesehatan Indonesia; 2014; 2(2):116-122.

10. Fitriana Y, Nurwiandani W. Asuhan Persalinan, Konsep Persalinan secara Komprehensif dalam Asuhan Kebidanan. Yogyakarta: PT. Pustaka Baru; 2018.

11. Saifuddin AB. Buku Acuan Nasional Pelayanan Kesehatan Maternal dan Neonatal. Jakarta: Yayasan Bina Pustaka Sarwono Prawirohardjo; 2009.

12. Notoatmodjo S. IImu Perilaku Kesehatan. Jakarta: Rineka Cipta; 2010. 